\title{
Long-term Turbulent Sensible-Heat-Flux Measurements with a Large-Aperture Scintillometer in the Centre of Łódź, Central Poland
}

\author{
Mariusz Zieliński ${ }^{1}$ - Krzysztof Fortuniak ${ }^{2}$ - Włodzimierz Pawlak ${ }^{2}$ • \\ Mariusz Siedlecki ${ }^{2}$
}

Received: 15 December 2016 / Accepted: 19 December 2017 / Published online: 11 January 2018

(C) The Author(s) 2018. This article is an open access publication

\begin{abstract}
We investigate the area-averaged sensible heat flux $\left(Q_{H}\right)$ obtained with a scintillometer along a 3.1-km path length over the city centre of Łódź, Central Poland. The annual cycle of $Q_{H}$ peaks in June but is lower by the middle of summer. In winter, due to a large amount of anthropogenic heat input, $Q_{H}$ remains positive all day long, with positive nighttime fluxes also found during months with frequent cold advection, e.g., June 2010. In the diurnal cycle of this flux, several features specific to urban areas are seen: the peak shifts 1-2 $\mathrm{h}$ after noon, the heat flux turns from positive to negative 1-2 $\mathrm{h}$ after sunset. In Łódź $Q_{H}$ was observed during inflow from the north and north-west, i.e. from the city centre. As this area is mostly covered with impervious materials, most of the heat exchanged between the ground and the overlying air is in the form of sensible heat flux. Under the conditions of inflow from the east and south-east, the maximum heat flux is approximately $100 \mathrm{~W} \mathrm{~m}^{-2}$ lower than during the inflow from the city centre, since more vegetation exists to the east and south-east of the scintillometer path. Cold and warm advection are found to be a vital factor in the observed heat-flux variability in the centre of Łódź.
\end{abstract}

Keywords Large-aperture scintillometer - Sensible heat flux - Surface energy balance Urban areas

\section{Introduction}

Knowledge of the specific climate of urban areas is necessary for a better understanding of the weather processes occurring in urban areas, as well as for the forecasting of weather conditions for densely populated areas. The land-atmosphere interactions have an impact

Mariusz Zieliński

mrzielinski@up.krakow.pl

1 Department of Sustainable Development and Shaping of Geographic Environment, Pedagogical University of Cracov, Podchorążych St 2, 30-084 Cracow, Poland

2 Department of Meteorology and Climatology, Faculty of Geographical Sciences, University of Łódź, Narutowicza 88, 90-139 Lodz, Poland 
on air quality, thermal comfort and even precipitation in cities. Moreover, urban planners and local authorities should include information on the city's influence on climate in their decisions concerning, e.g., designing new settlements, roads, parks etc.

One of the best-known modifications of local climate by cities is the urban-heat-island effect (e.g. Oke 1982). The increase of air temperature in densely built-up districts, as compared to the city surroundings, is tailored to the specific surface energy balance of urban areas. The impacts of urban areas on energy balance constituents are complex. For instance, high pollution can reduce the incoming downward radiation (Oke 1988; Stanhill and Kalma 1995), but a large quantity of dark surfaces (e.g. tarred roofs) reduces the magnitude of reflected shortwave radiation (e.g. Christen and Vogt 2004). A small fraction of vegetation cover in the city centres frequently contributes to a decrease in turbulent latent heat flux and significant enhancement of turbulent sensible heat flux (Christen and Vogt 2004; Offerle et al. 2006b; Goldbach and Kuttler 2013). Therefore, there is still a need for long-term energy balance measurements at different scales.

Most observations of turbulent heat fluxes in urban areas have been performed using the eddy-covariance method (e.g. Christen and Vogt 2004; Offerle et al. 2006a, b; Goldbach and Kuttler 2013; Nordbo et al. 2013; Ward et al. 2013; Kotthaus and Grimmond 2014a, b). Eddy covariance is a point-based method and provides fluxes representative of relatively small areas (e.g. Kotthaus and Grimmond 2014b; Ward et al. 2014). An alternative for eddy covariance is the scintillation method providing an area-averaged heat flux that can be representative of larger areas, even at the scale of numerical weather prediction model grid cells i.e. 5-10 km (e.g. Beyrich et al. 2012; Ward et al. 2014).

Scintillometry has been in use for several decades; however, it was not until the end of the 1990s that it was used in cities for the first time (Kanda et al. 2002). The reliability of scintillometers to provide accurate estimates on surface fluxes has been proven in many different natural or semi-natural areas (e.g. Thiermann and Grassl 1992; Green et al. 1994; De Bruin et al. 1995; Beyrich et al. 2002, 2012; Meijninger et al. 2006; Ezzachar et al. 2007; Evans et al. 2012; Samain et al. 2012).

Over several years, scintillometers have become more frequently used in urban areas. The first measurements with a small-aperture scintillometer (SAS) was performed in Tokyo (Kanda et al. 2002), while measurement campaigns using SAS instruments have also taken place in Basel (Roth et al. 2006; Salmond et al. 2012) and London (Pauscher 2010). The SAS instrument provides fluxes averaged over relatively short paths (up to $250 \mathrm{~m}$ ), and to obtain fluxes representative of larger areas, a large-aperture scintillometer (LAS) should be used. The LAS instrument has been used in a number of cities, e.g., Marseille (Lagouarde et al. 2006), London (Wood et al. 2013a), Helsinki (Wood et al. 2013b), Łódź (Zieliński et al. 2013), Swindon (Ward et al. 2014), and Changzou (Zhang and Zhang 2015), London (Crawford et al. 2017). More recently, Ward et al. (2015a, b) used a system consisting of a LAS intrument and a microwave scintillometer to measure the sensible and latent heat fluxes simultaneously over the city of Swindon in the UK.

The main objective of the present paper is to investigate the temporal and, to some extent, spatial variability of the turbulent sensible heat flux in the centre of Łódź. Frequently, the observed variability of sensible heat flux in relation to wind direction is associated with different land-surface cover. Herein, we wish to investigate to what extent weather conditions, especially cold and warm air advection over the city, affect this variability. Section 2 provides a theoretical background of sensible-heat-flux retrieval from scintillometer data, together with experimental details; the scintillometer source area is discussed in Sect. 3. The temporal variability of sensible heat flux is analyzed in Sect. 4, and the directional dependence of sensible heat flux discussed in Sect. 5. 


\section{Data and Methods}

\subsection{Sensible-Heat-Flux Retrieval from Scintillometer Measurements}

The LAS instrument provides estimates of the structure parameter of the refractive index of air $\left(C_{n}^{2}\right)$. This structure parameter is not measured directly, but is related to the variance of the natural logarithm of intensity $\left(\sigma_{\ln I}^{2}\right)$ obtained by the LAS receiver (Wang et al. 1978). However, when optical turbulence is too intense, this relation becomes invalid, a phenomenon referred to as the saturation of the signal (e.g. Clifford et al. 1974; Frehlich and Ochs 1990; Ochs and Wilson 1993). When saturation occurs, $\sigma_{\ln I}^{2}$ is stabilized at a certain level despite the increasing strength of scintillation; saturation is more likely to occur if the LAS instrument is mounted relatively low over a long path (Hartogensis et al. 2003). The LAS measurements can be made on paths ranging in length from 0.25 to $5 \mathrm{~km}$. The structure parameter $C_{n}^{2}$ is related to the structure parameters of temperature $\left(C_{T}^{2}\right)$, humidity $\left(C_{Q}^{2}\right)$ and the covariance between them $\left(C_{T Q}^{2}\right)$ (see e.g. Hill et al. 1980). For near-infrared wavelengths, $C_{n}^{2}$ depends mostly on temperature fluctuations, and humidity effects may be accounted for using the so-called Bowen-ratio correction (Wesely 1976; Moene 2003),

$$
C_{n}^{2} \approx\left(\frac{p \gamma}{\bar{T}^{2}}\right)^{2} C_{T}^{2}\left(1+\frac{0.03}{\beta}\right)^{2}
$$

where $T$ is air temperature $(\mathrm{K}), \gamma$ is the refractive index coefficient for air $\left(7.9 \times 10^{-7} \mathrm{KPa}^{-1}\right)$, $p$ is atmospheric pressure (Pa), and $C_{n}^{2}$ and $C_{T}^{2}$ have units of $\mathrm{m}^{-2 / 3}$ and $\mathrm{Km}^{-2 / 3}$, respectively.

Monin-Obukhov similarity theory (MOST) makes it possible to link $C_{T}^{2}$ and the areaaveraged sensible heat flux $Q_{H}$, and first, the temperature scale $T_{*}$ is computed from $C_{T}^{2}$ (e.g. Wyngaard et al. 1971),

$$
\frac{C_{T}^{2}\left(z_{\mathrm{eff}}\right)^{2 / 3}}{T_{*}^{2}}=f_{T T}\left(\frac{z_{\mathrm{eff}}}{L}\right),
$$

where $z_{\mathrm{eff}}$ is the effective height of the scintillometer beam above the surface $(\mathrm{m}), L$ is the Obukhov length (m) and $f_{T T}$ is a MOST function. For more details on the $z_{\text {eff }}$ derivation, see Hartogensis et al. (2003), with $L$ defined as

$$
L=\frac{u_{*}^{2} T}{g \kappa T_{*}},
$$

where $g$ is the acceleration due to gravity (taken as $9.81 \mathrm{~m} \mathrm{~s}^{-2}$ ), $u_{*}$ is the friction velocity $\left(\mathrm{m} \mathrm{s}^{-1}\right)$ and $\kappa$ is the von Kármán constant $(0.40)$.

The wind profile adjusted for stability can be used for the computation of $u_{*}$,

$$
u_{*}=u\left(z_{m}\right) \kappa\left[\ln \left(\frac{z_{m}-z_{d}}{z_{0}}\right)-\Psi_{m}\left(\frac{z_{m}}{L}\right)+\Psi_{m}\left(\frac{z_{0}}{L}\right)\right]^{-1},
$$

where $u$ is mean wind speed $\left(\mathrm{m} \mathrm{s}^{-1}\right), z_{m}$ is the measurement height $(\mathrm{m}), z_{d}$ is the displacement height (m), $z_{0}$ is the aerodynamic roughness length (m), and $\Psi_{m}$ is the well-known BussingerDyer stability function.

The most commonly used forms for the similarity function in Eq. 2 are those of Wyngaard et al. (1971); however, a range of parameters can be found in the literature. For unstable conditions, the MOST function has the following form,

$$
f_{T T}(\zeta)=c_{T 1}\left(1-c_{T 2} \zeta\right)^{-2 / 3},
$$


while for stable conditions,

$$
f_{T T}(\zeta)=c_{T 3}\left(1+c_{T 4}(\zeta)^{2 / 3}\right)
$$

Andreas (1988) adjusted the values for $c_{T 1}=4.9, c_{T 2}=6.1$ and $c_{T 3}=4.9, c_{T 4}=2.2$, previously given by Wyngaard et al. (1971) to reflect $\kappa=0.4$, while De Bruin et al. (1993) gave different values i.e. $c_{T 1}=4.9, c_{T 2}=9$ and $c_{T 3}=4.9, c_{T 4}=0$. Hill et al. (1992) for unstable conditions found these parameters to be nearly twice as large as previously reported, i.e. $c_{T 1}=8, c_{T 2}=15$, and more recently Kooijmans and Hartogensis (2016) used measurements from 11 scintillometer field campaigns and determined parameters for both unstable $\left(c_{T 1}=5.6, c_{T 2}=6.5\right)$ and stable $\left(c_{T 3}=5.5, c_{T 4}=1.1\right)$ conditions. However, their investigation did not include data from urban areas. The choice of similarity function is crucial for the estimation of $Q_{H}$, and we found that for unstable conditions $Q_{H}$ computed with the function presented by De Bruin et al. (1993) was on average 10 and $30 \%$ higher than $Q_{H}$ obtained using the function given by Andreas (1988) and Hill et al. (1992), respectively. This is consistent with other studies (e.g. Lagouarde et al. 2006; Ward et al. 2014). Since both $u_{*}$ and $T_{*}$ are connected via $L$, their ultimate values must be solved iteratively using Eqs. 2-6. Finally, $Q_{H}$ can be obtained from

$$
Q_{H}=-\rho c_{p} u_{*} T_{*},
$$

where $\rho$ is air density $\left(\mathrm{kg} \mathrm{m}^{-3}\right)$ and $c_{p}$ is the specific heat of moist air at constant pressure $\left(\mathrm{J} \mathrm{kg}^{-1} \mathrm{~K}^{-1}\right)$.

The scintillometer provides only absolute values of $Q_{H}$, so additional measurements have to be performed simultaneously in order to determine flux sign. Samain et al. (2012) compared several algorithms for the determination of the sign of $Q_{H}$, and concluded that the algorithm based on $C_{n}^{2}$ and the radiation balance is most appropriate for their dataset. As will be shown below, this approach had to adjusted for our data processing.

\subsection{Measurement Sites and Data Processing}

Measurements were conducted at Łódź $\left(51^{\circ} 47^{\prime} \mathrm{N}, 19^{\circ} 28^{\prime} \mathrm{E}\right)$, a city located in central Poland, about $120 \mathrm{~km}$ south-west of Warsaw, the capital of Poland. In the last decade, the population of Łódź has decreased and, continues to decrease; now it has approximately 700,000 residents. The city centre is occupied by 3-5-storey buildings (about 15-20 $\mathrm{m}$ in height), built mainly at the turn of the twentieth century. The old city centre is surrounded by industrial areas, residential areas with relatively low buildings (1 or 2 storeys) and districts of blocks of flats (some reaching up to 10 storeys). In the surroundings of the city centre there are many green parks, with the largest located west of the city centre.

The scintillometer used was a BLS 900 instrument (Scintec AG, Rottenburg, Germany), i.e. a large-aperture scintillometer. The LAS instrument was deployed in the centre of Łódź with a measurement path of $3142 \mathrm{~m}$ in length (Fig. 1), while the LAS transmitter was mounted $31 \mathrm{~m}$ above the ground on a mast standing on a 17-m high building located at 81 Lipowa St. $\left(51^{\circ} 45^{\prime} 45^{\prime \prime} \mathrm{N}, 19^{\circ} 26^{\prime} 43^{\prime \prime} \mathrm{E}, 204 \mathrm{~m}\right.$ a.s.1.). On the same mast, $6 \mathrm{~m}$ above the LAS transmitter, an eddy-covariance system and a net radiometer were also mounted, with the LAS receiver deployed on the roof of a 36-m high building at 21/23 Matejki St. $\left(51^{\circ} 46^{\prime} 32^{\prime \prime} \mathrm{N}, 19^{\circ} 29^{\prime} 08^{\prime \prime} \mathrm{E}\right.$, $227 \mathrm{~m}$ a.s.1.). Not only was the path slanted but also its actual height above the ground was not uniform. Consequently the effective measurement height $z_{\text {eff }}$ of the LAS was estimated in an iterative procedure according to Hartogensis et al. (2003), 


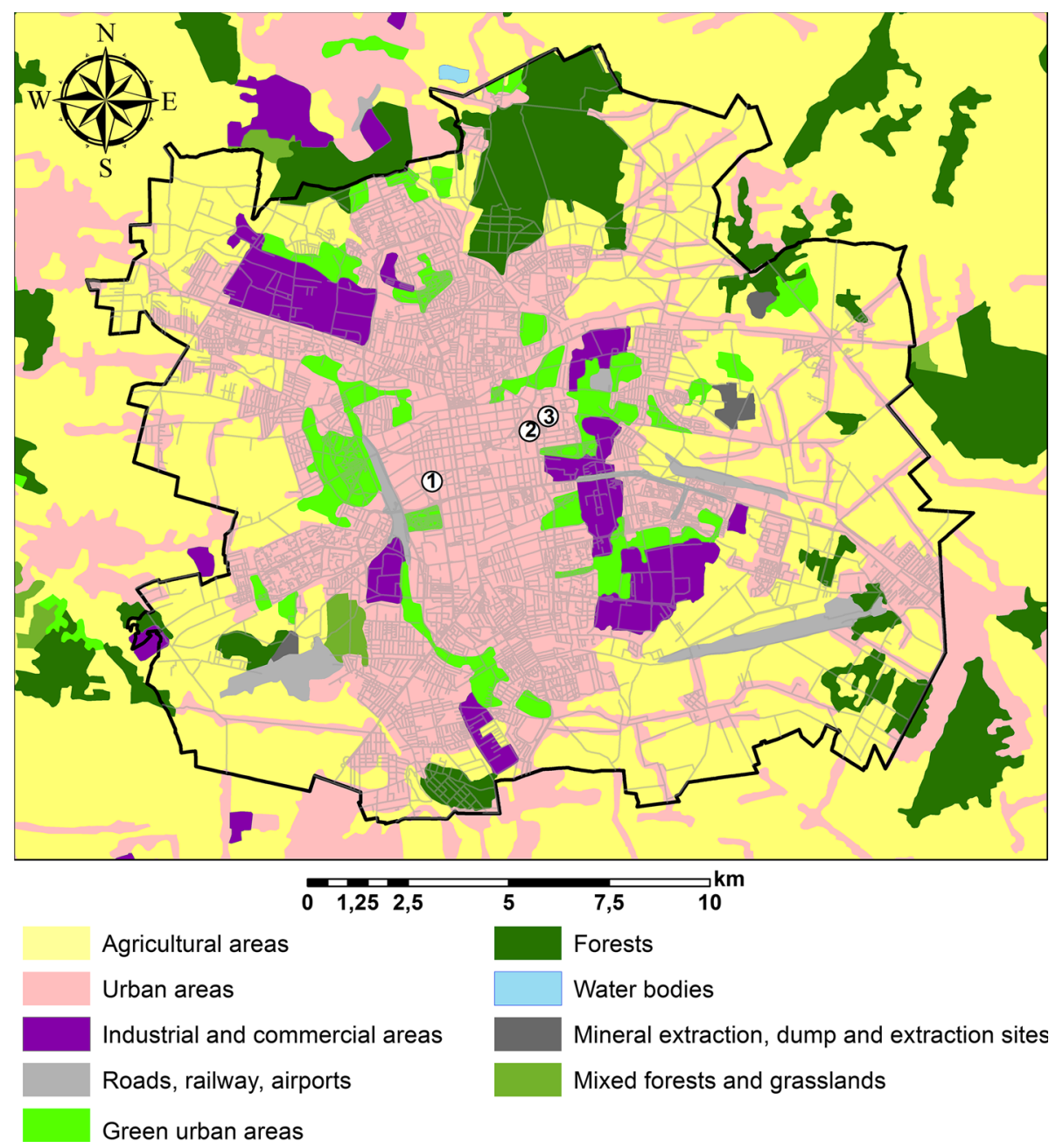

Fig. 1 Location of measurement sites shown on a land-use/land-cover map based on the Corine Land Cover 2006. (1) scintillometer transmitter and eddy-covariance system (Lipowa), (2) eddy-covariance system (Narutowicza), (3) scintillometer receiver

$$
z_{\mathrm{eff}}^{-2 / 3} f_{T T}\left(\frac{z_{\mathrm{eff}}}{L_{O B}}\right)=\int_{0}^{1}\left(z_{M}(x)-z_{d}(x)\right)^{-2 / 3} f_{T T}\left(\frac{\left(z_{M}(x)-z_{d}(x)\right)}{L_{O B}}\right) P W F(x) \mathrm{d} x,
$$

where $z_{M}(x)$ is the beam height at distance $x$ from the transmitter, $z_{d}(x)$ is the displacement height at distance $x$ from the transmitter and $P W F(x)$ is the scintillometer path-weighting function for $x$.

Once the large variability of the height of buildings and elevations on both sides of the LAS path was found, we decided to estimate $z_{\text {eff }}$ and aerodynamic parameters $z_{0}$ and $z_{d}$ in three zones (two for the wind direction perpendicular and one for the wind direction parallel to the optical path). As shown by Zieliński et al. (2017), this approach only slightly decreases the uncertainties in $Q_{H}$ resulting from the large difference in average building 
Table 1 Measurement height $\left(z_{m}\right)$, mean effective height $\left(z_{\text {eff }}\right)$, mean building height $\left(z_{H}\right)$, displacement height $\left(z_{d}\right)$, roughness length $\left(z_{0}\right)$ for the scintillometer (three zones separately)

\begin{tabular}{llll}
\hline Parameter $[\mathrm{m}]$ & \multicolumn{2}{l}{ Wind direction } & \\
\cline { 2 - 4 } & $080^{\circ}-225^{\circ}$ & $045^{\circ}-080^{\circ}, 225^{\circ}-260^{\circ}$ & $260^{\circ}-360^{\circ}, 0^{\circ}-045^{\circ}$ \\
\hline$z_{m}$ & $33.8^{* *}$ & $34.4^{* *}$ & $36.3^{* *}$ \\
$z_{\text {eff }}$ & $24.6(0.2)^{*}$ & $24.5(0.3)^{*}$ & $25.4(0.1)^{*}$ \\
$z_{H}$ & $11.7^{* *}$ & $13.7^{* *}$ & $15.4^{* *}$ \\
$z_{d}$ & $8.2^{* *}$ & $9.6^{* *}$ & $10.8^{* *}$ \\
$z_{0}$ & $1.2^{* *}$ & $1.4^{* *}$ & $1.5^{* *}$
\end{tabular}

* Mean $z_{\text {eff }}$ obtained for unstable conditions from iterative procedure; standard deviation provided in brackets **Average value obtained from profiles along LAS path, where each single value of the parameter at a certain location was multiplied by the corresponding value of the scintillometer-path weighting function

height and elevation on both sides of the LAS path. For the estimation of mean building height $z_{H}$ the digital surface model was used. Both $z_{0}$ and $z_{d}$ were estimated as a fraction of $z_{H}$ i.e. $z_{0}=0.1 z_{H}$ and $z_{d}=0.7 z_{H}$, as suggested by Grimmond and Oke (1999). Table 1 summarizes $z_{\mathrm{eff}}, z_{H}, z_{d}$ and $z_{0}$ obtained for different zones.

An additional eddy-covariance system and net radiometer were mounted on a mast at 88 Narutowicza St. (51 $46^{\prime} 24^{\prime \prime} \mathrm{N}, 19^{\circ} 28^{\prime} 52^{\prime \prime} \mathrm{E}, 221 \mathrm{~m}$ a.s.l.) at a height of $42 \mathrm{~m}$ above the ground. For more details on both eddy-covariance towers and eddy-covariance data processing, see Pawlak et al. (2011), Fortuniak et al. (2013) and Pawlak and Fortuniak (2016).

The LAS data were collected during the period 26 August 2009-26 November 2012, but due to many technical issues the time series is not gap-free (e.g. renovation of the building hosting the LAS receiver that took place in 2011 and 2012). Measurements were not made between 1 December 2009 and 10 June 2010, and from 6 November 2010 to 5 April 2011. Due to unfavourable weather conditions, maintenance, etc., several shorter gaps were present in the time series as well.

The LAS instrument operated at $125-\mathrm{Hz}$ frequency with data integrated in 1-min blocks. During the LAS operation, the saturation correction proposed by Clifford et al. (1974), as well as the extinction and outer scale corrections, were applied, both included in BLS900 software. The average saturation correction was about $2.5 \%$, and according to the criterion of Frehlich and Ochs (1990), less than $0.01 \%$ of our data suffered from saturation.

The $Q_{H}$ value was computed iteratively based on Eqs. 2-7. The auxiliary data necessary for the estimation of $Q_{H}$, i.e. temperature, atmospheric pressure etc., were available with 15-min resolution; therefore $C_{n}^{2}$ values were averaged initially at 15-min intervals (simple block average) and then in 1-h blocks. For the calculation of $C_{T}^{2}$, air temperature $(T)$ obtained from sonic anemometers at two towers (see Fig. 2) was used.

In urban areas, it is difficult to obtain representative values of anthropogenic heat flux and storage heat that are required for the Bowen-ratio $(\beta)$ estimation in the iterative procedure described above. Thus, for the Bowen-ratio correction to $C_{T}^{2}$ we used $\beta$ values from both eddy-covariance towers. For low absolute $\beta$ values, i.e. $|\beta| \leq 0.5$, the correction was not applied (see Moene 2003).

The LAS source area lies in the city centre, but both eddy-covariance towers are located at the opposite edges of the city core. To provide better representativeness of auxiliary data from the eddy-covariance towers for the $Q_{H}$ (from LAS) computation for the wind directions $330^{\circ}-$ $130^{\circ}, T$ and $\beta$ were taken from the Lipowa station and for the remaining wind directions those parameters were taken from the Narutowicza station. The friction velocity was computed from 


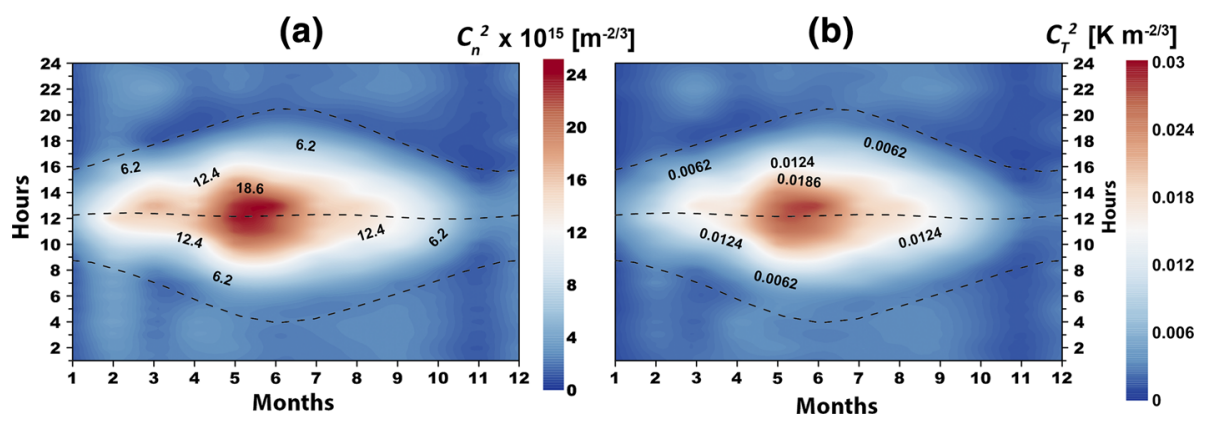

Fig. 2 Mean diurnal and annual cycles of, a refractive index structure parameter $C_{n}^{2}$, and $\mathbf{b}$ temperature structure parameter $C_{T}^{2}$ in Łódź

the logarithmic wind profile using the wind speed measured at the Narutowicza station, since at Lipowa the flow might be disturbed by urban canyons for certain wind directions. For the computation of $u_{*}, z_{0}$ and $z_{d}$ were estimated in three zones (for more details, see Zieliński et al. 2017).

One of the drawbacks of the scintillometer is that it provides only the absolute flux value, and its direction must be determined from additional measurements. There are several different algorithms to compute the sign of the flux (e.g. Samain et al. 2012). Ward et al. (2014) determined the $Q_{H}$ sign based on the diurnal cycle of $C_{n}^{2}$ for the dataset gathered in the suburbs of Swindon, UK. $C_{n}^{2}$ usually has the local minima close to sunrise and sunset (Tunick et al. 1994), and thus such local minima are considered as a transition period from stable to unstable conditions and vice versa (Samain et al. 2012).

In the considered dataset, only the evening minimum was clearly pronounced (Fig. 2), and therefore we were not able to determine the flux direction correctly based on the diurnal cycle of $C_{n}^{2}$. Instead, we used the sign of $Q_{H}$ measured at the eddy-covariance towers. As in the case of air temperature, we used the data from the Lipowa station for the sector $330^{\circ}-$ $130^{\circ}$ and from the Narutowicza station for the remaining wind directions. Despite the fact that the source areas of both eddy-covariance towers and the LAS instrument have slightly different characteristics and size, we believe that this approach is justified. This algorithm makes it possible to automate the determination of the flux direction; however there were some cases when it failed. Therefore, the whole time series was checked and compared with the diurnal cycle of $C_{n}^{2}$ and the radiation balance values. For seven cases, we found distinct minima in $C_{n}^{2}$ indicating a transition from stable to unstable conditions or vice versa which were not reflected in the $Q_{H}$ sign. Therefore, we adjusted the sign of the flux for those cases. For sites with no additional eddy-covariance system, temperature profile measurements or at least temperature measurements at two different levels can be helpful in determining the sign of $Q_{H}$ from the scintillometer.

In general, there is a high correlation between $Q_{H}$ determined from the LAS instrument and eddy-covariance measurements $\left(r^{2}=0.87\right.$ for Narutowicza station and $r^{2}=0.76$ for Lipowa station). Previous results from Łódź also confirms high agreement of $Q_{H}$ from LAS and eddy-covariance methods (Zieliński et al. 2013). However, due to significant differences in source areas of both eddy-covariance sites and the LAS instrument e.g. west of Lipowa station there is a high vegetation fraction, while during the inflow from the west, the LAS source area comprises the old city centre. It is thus difficult to provide the overall uncertainty in $Q_{H}$ from LAS measurements. 
Table 2 Summary of data quality control

\begin{tabular}{lclll}
\hline Month & $\begin{array}{l}\text { Number of } \\
\text { available 1-h } \\
\text { blocks }\end{array}$ & $\begin{array}{l}\text { Available 1-h blocks as } \\
\text { percent of possible data } \\
\text { that could be collected in } \\
\text { period September 2009- } \\
\text { November 2012 }\end{array}$ & $\begin{array}{l}\text { Number of 1-h } \\
\text { blocks that passed } \\
\text { quality control }\end{array}$ & $\begin{array}{l}\text { Number of 1-h } \\
\text { blocks that passed } \\
\text { quality control } \\
\text { as a percent of } \\
\text { collected data. }\end{array}$ \\
\hline January & 425 & 19.0 & 325 & 76.5 \\
February & 356 & 17.5 & 248 & 69.7 \\
March & 327 & 14.7 & 253 & 77.4 \\
April & 929 & 43.0 & 730 & 78.6 \\
May & 1485 & 66.5 & 1166 & 78.5 \\
June & 1751 & 81.1 & 1225 & 70.0 \\
July & 1675 & 75.0 & 1125 & 67.2 \\
August & 1934 & 81.4 & 1347 & 69.6 \\
September & 2152 & 74.7 & 1660 & 77.1 \\
October & 2274 & 76.4 & 1785 & 78.5 \\
November & 1396 & 48.5 & 832 & 59.6 \\
December & 282 & 12.6 & 163 & 57.8 \\
Annual & 14,986 & 52.3 & 10,859 & 72.5 \\
\hline
\end{tabular}

The collected scintillometer data underwent a detailed quality control procedure. Data were rejected from further analyses, (1) data were stored with errors (e.g. misalignment), (2) auxiliary data were unavailable, (3) precipitation or unfavourable weather conditions (e.g. fog) occurred, (4) if the eddy-covariance data did not pass stationarity tests (for more details on eddy-covariance data processing, see Fortuniak et al. 2013; Zieliński et al. 2013). In general, $27.5 \%$ of collected data did not pass the quality control (Table 2, Fig. 3). The largest relative number of high quality data were available for January, March, April, May and September, i.e. more than $75 \%$ of them passed the quality control. On the other hand, the largest number of data that failed the quality control were taken in November and December, 40 and $42 \%$, respectively.

\section{Scintillometer Source Area}

Footprint analysis can provide valuable information regarding the surface that contributes most to the measured sensible heat flux. So far many different footprint models have been developed, e.g. Horst and Weil (1992), Schmid (1994), Leclerc et al. (1997), Hsieh et al. (2000). In urban areas one of the most commonly used footprint model is the 3D analytical Flux Source Area Model (FSAM) developed by Schmid (1994, 1997), and successfully applied for single-point measurements in cities (e.g. Grimmond et al. 2004; Offerle et al. 2006a, b; Pawlak et al. 2011; Goldbach and Kuttler 2013; Kotthaus and Grimmond 2014b).

For the scintillometer source-area estimation, the path-weighting function must be included, and therefore, the footprint models for single-point measurements cannot be applied directly to the scintillometer data. The scintillometer source area is often estimated as a combination of the footprint modelling performed for discrete points along the optical path and the path-weighting function (e.g. Meijninger et al. 2002; Göckede et al. 2005; Hoedjes et al. 

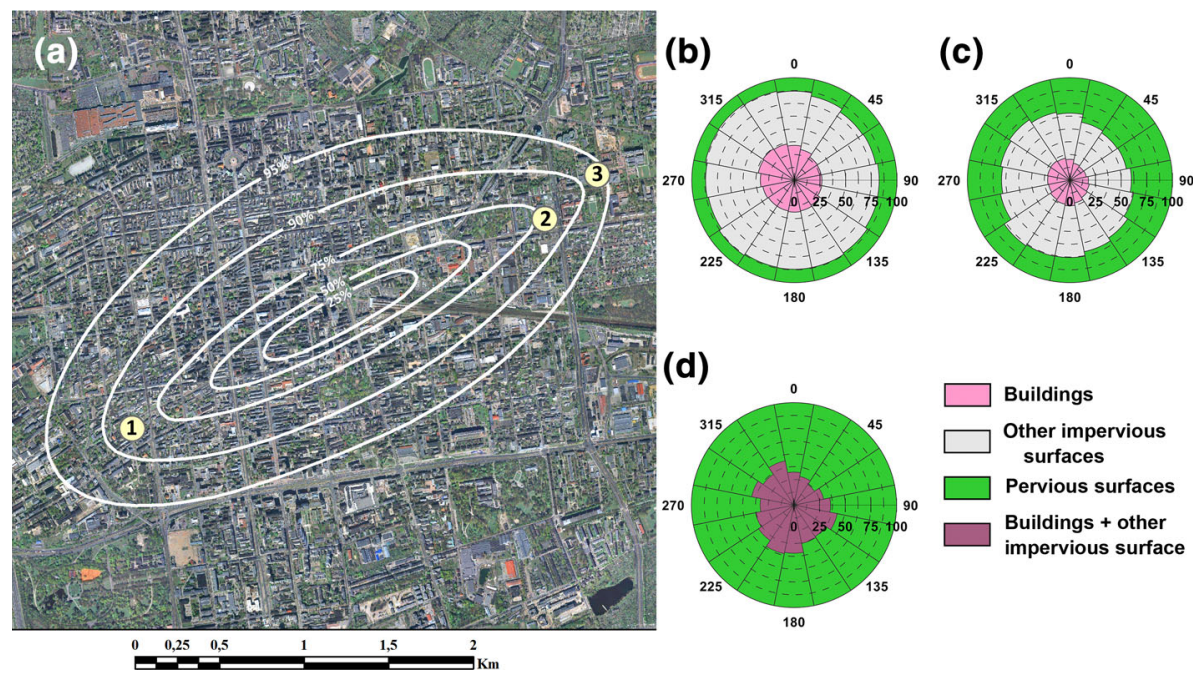

(d)
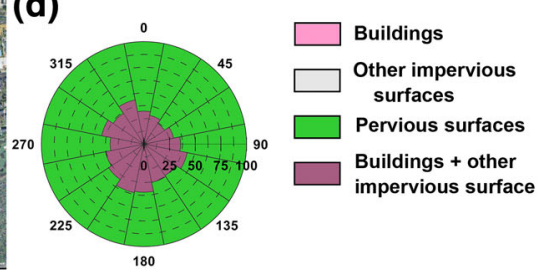

Fig. 3 Ensemble scintillometer source area at $95 \%$ (a) and surface cover fraction for $30^{\circ}$ intervals under unstable (b), near-neutral (c) and stable (d) conditions.

2007; Timmermans et al. 2009; Evans et al. 2012; Ward et al. 2014). Here a similar approach is applied, and in order to estimate the LAS source area, footprint modelling using the FSAM model was performed for discrete points located every $32 \mathrm{~m}$ along the optical path (the LAS path was divided into 100 points). The modelled footprint for each point was multiplied by the respective value of the LAS path-weighting function, and then summed over the whole path.

Under unstable conditions, the LAS source area comprising $95 \%$ of the footprint is located over the most densely built-up areas of Łódź (Fig. 3a). The 95\% ensemble footprint covers an area of approximately $4.7 \mathrm{~km}^{2}$, although under near-neutral or stable conditions it potentially covers an area of up to several tens of $\mathrm{km}^{2}$. The LAS source area is shifted towards the transmitter, which is the result of the topography (closer to the transmitter the LAS path traversed lower than when closer to the receiver) and the dominant wind direction (western and southern sectors). The centre of the average LAS source area is shifted about $170 \mathrm{~m}$ to the south-west in relation to the optical path centre point.

An artificial surface cover dominates in the LAS source area under unstable conditions, especially in its western part that includes the oldest part of Łódź. On average, buildings cover $33 \%$ of the source area at $p=95,48 \%$ is covered with other impervious surfaces, e.g. streets, pavements, car parks, and only $19 \%$ involves pervious surfaces covered with vegetation.

The directional characteristics of the surface cover for different stabilities show many similarities. Under unstable conditions, when the LAS source area shrinks to several $\mathrm{km}^{2}$, the fraction of pervious surfaces ranges from 10 to $20 \%$ of the source area. The largest share of impervious surfaces was observed for the northern, north-western, western, southwestern and southern inflow. As the source area centre lies to the east of the city centre's dense settlement, for these directions the share of impervious surfaces is the largest. Under unstable conditions, when an easterly flow exists, the vegetation fraction is almost $7 \%$ larger than for north-western inflow (Fig 3b). When the stability approached neutral, the source area became extended, comprising more pervious surfaces outside the city centre. Therefore, 
for near-neutral conditions the vegetation fraction is more than twice as large as for unstable conditions, e.g. for north-western inflow vegetation covered approximately $45 \%$ of the LAS source area (Fig. 3c). For stable conditions the pervious surfaces dominated for every wind direction, with a maximum share (75\%) for the north-eastern inflow (Fig. 3d). The high share of pervious surfaces under stable conditions results from the fact that for stable stratification, the source area extends significantly farther than for unstable or near-neutral conditions. For weak wind conditions, the LAS source area covered up to $60-70 \mathrm{~km}^{2}$ and comprised much natural or semi-natural land cover outside the city.

\section{Temporal Variability of Turbulent Sensible Heat Flux}

\subsection{Weather Conditions During the Measurement Campaign}

Figure 4 presents monthly average air temperature (Fig. 4a) and monthly precipitation (Fig. 4b) totals during the measurement campaign against the background of long-term (19812010) observations from the Łódź-Lublinek station (located approximately $5 \mathrm{~km}$ south-east of the Lipowa site). Taking into account the whole measurement campaign, air temperature $T$ does not deviate significantly from the 30-year average (1981-2010) except for winter months. In January 2010, December 2011 and February $2012 \mathrm{~T}$ is even several ${ }^{\circ} \mathrm{C}$ lower than the long-term averages. During spring and autumn, $T$ is almost the same magnitude as the 30-year average, while in summer, $T$ is relatively high $\left(1-2{ }^{\circ} \mathrm{C}\right.$ higher than the 30 -year average) except for July 2011, when $T$ is below the long-term average and even smaller than values in June 2011.

For monthly precipitation, larger deviations from the 30 -year averages are observed. In general, the precipitation totals are relatively low, except for 2010 when annual rainfall was the highest recorded in Łódź in the period 1981-2010. In October 2009, March, May and September 2010 the monthly precipitation totals exceed $150 \%$ of the 30 -year average and in November 2010 the total even exceeds $200 \%$ of the long-term average. On the other hand, little precipitation occurred in October 2011 (about 14\% of 30-year average), November 2011 (almost no precipitation), late spring and summer 2012 (30-53\%).

For the wind speed and direction (Fig. 4c), significant differences in their distribution between both eddy-covariance stations are found. At the Lipowa station, the domination of western and north-western directions is observed. An inflow from approximately the south and south-east is also frequent. At the Lipowa station, low frequency of inflow from the directions parallel to streets is observed, probably resulting from the flow disturbance due to the urban canyons (Fortuniak et al. 2013). The wind rose chart for the Narutowicza site is more representative of the long-term wind conditions observed in Central Poland. During the analyzed period, the inflow from the western sector dominates; however, the inflow from the south-east is almost as frequent as from the west. The north-eastern inflow is the least frequent; moreover, the inflow from that direction occurs mainly in winter. At both sites, the episodes with low wind speed $\left(<1 \mathrm{~m} \mathrm{~s}^{-1}\right)$ are very rare $(2-4 \%)$, while periods with wind speeds $>3 \mathrm{~m} \mathrm{~s}^{-1}$ are the most frequent; the average wind speed at Lipowa is found to be $3 \mathrm{~m} \mathrm{~s}^{-1}$ and at Narutowicza this is $3.6 \mathrm{~m} \mathrm{~s}^{-1}$. Worth noting is the fact that the wind speed and direction do not deviate significantly from the longer period averages (Fortuniak et al. 2013). 


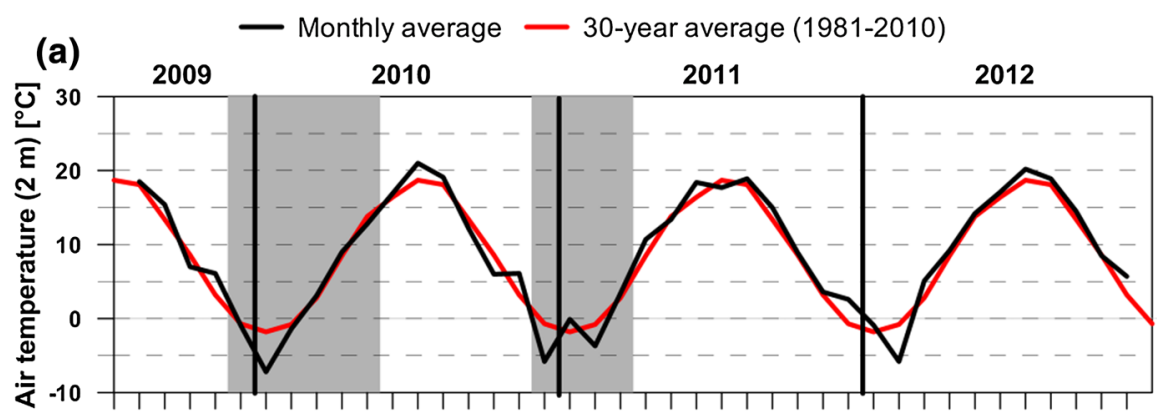

ASONDJFMAMJ JASONDJFMAM J JASONDJFMAMJ JASON Months

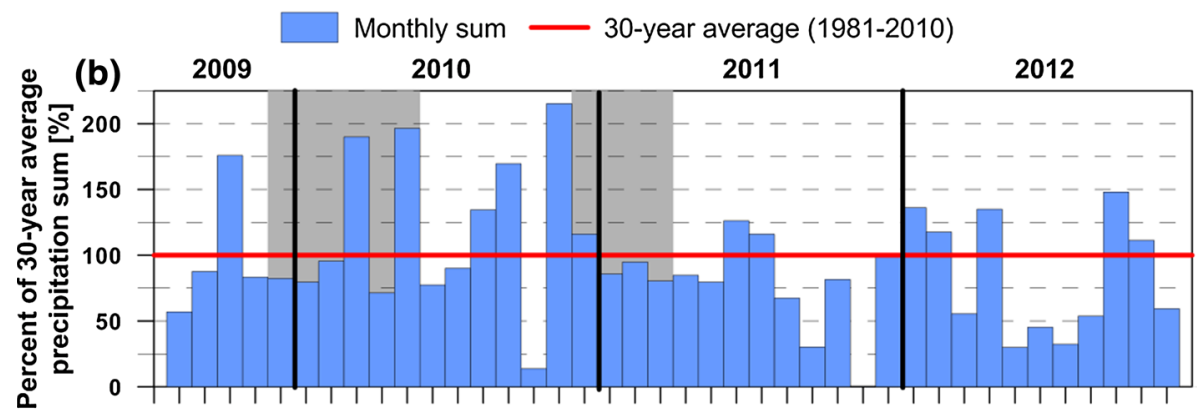

ASONDJFMAMJ JASONDJFMAM J JASONDJFMAMJ JASON Months
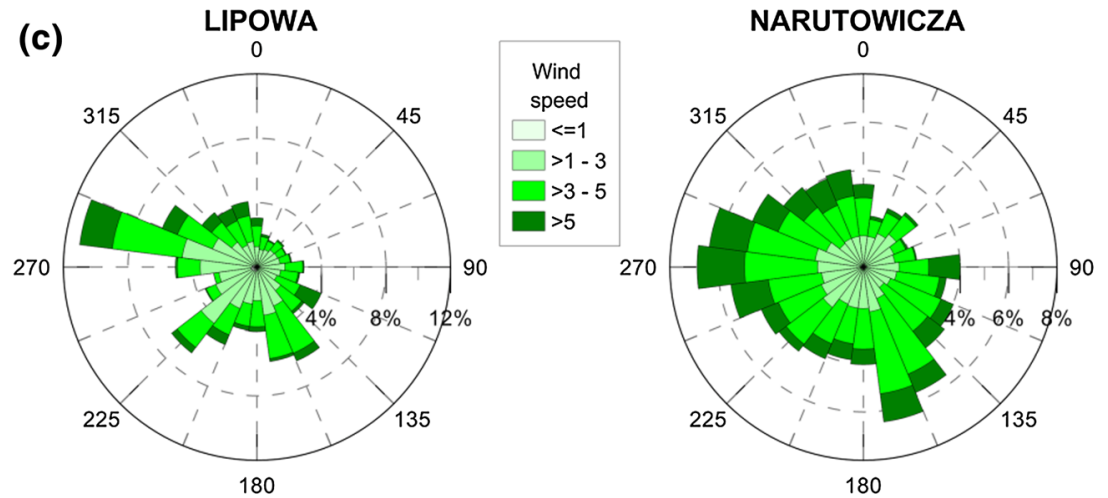

Fig. 4 Air temperature (a) and precipitation (b) during the measurement campaign against the background of 30-year averages (1981-2010). Air temperature and precipitation data presented here were obtained at ŁódźLublinek Airport about $5 \mathrm{~km}$ south-west of the LAS transmitter. Periods with no LAS data are highlighted in grey. Frequency distribution of wind speed by wind direction for Lipowa and Narutowicza sites during the measurement campaign (c)

\subsection{Monthly Variability of Turbulent Sensible Heat Flux}

In Fig. 5, the average diurnal cycles of $Q_{H}$ and net radiation $Q^{*}$ for the whole measurement campaign are shown, noting that the first half of the year suffers from a lack of sufficient data. Nevertheless, a large variability of $Q_{H}$ from year to year is observed. In 2010 and 


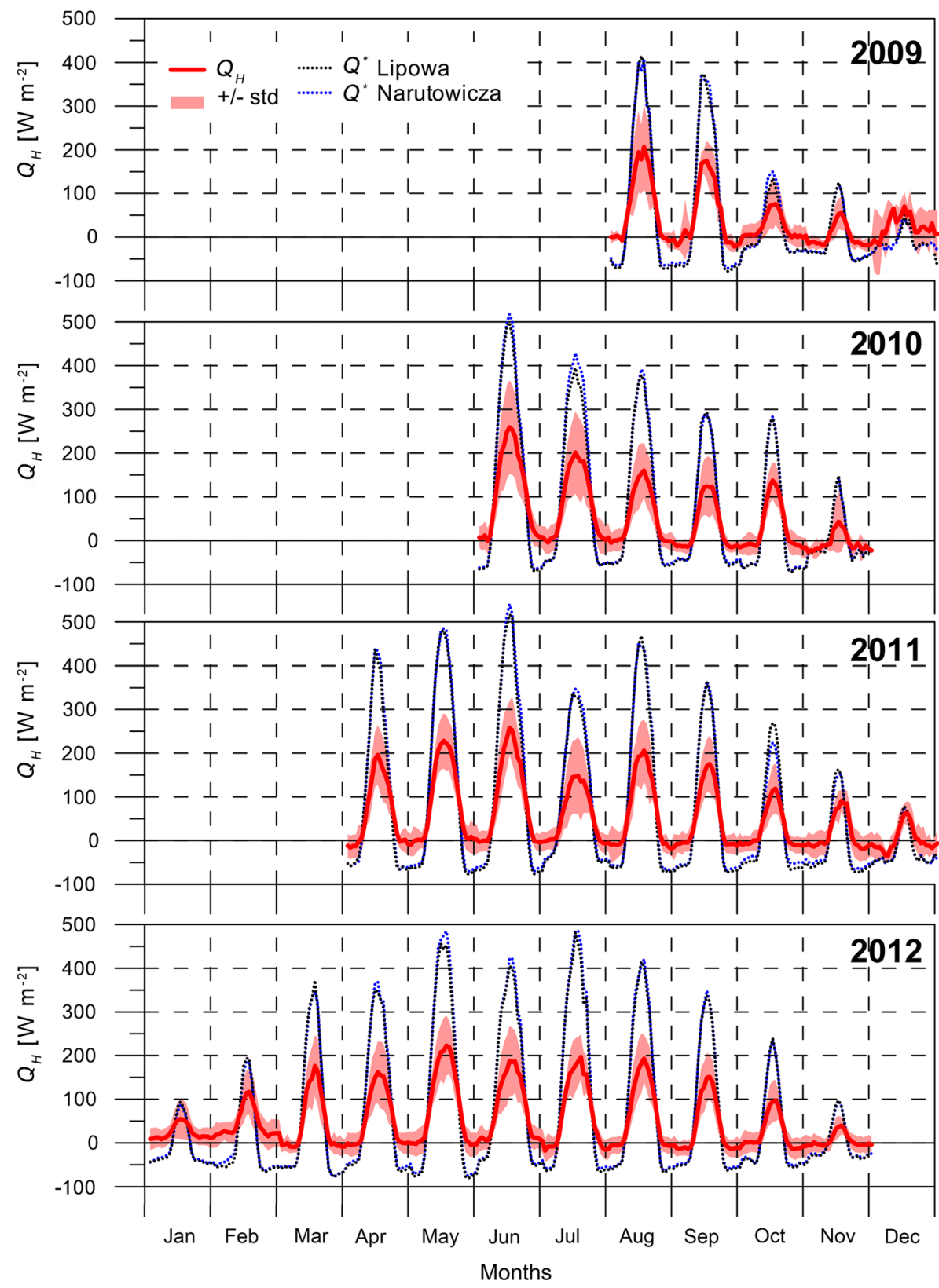

Fig. 5 Temporal variation of turbulent sensible heat flux $Q_{H}$ measured with the scintillometer in Łódź in the period 2009-2011. Dashed lines indicate the net radiation $Q^{*}$ measured on masts at Lipowa and Narutowicza stations. In addition \pm 1 standard deviation of $Q_{H}$ is highlighted

2011, the largest $Q_{H}$ is observed in June; however, for 2010 the magnitude for the previous months remains unknown; in 2012, the maximum shifted to May. Similar results were found for Swindon, UK (Ward et al. 2014), where in 2012 the largest $Q_{H}$ was also observed in 
May. For Łódź, the relatively small $Q_{H}$ observed in June 2012 is a result of high cloudiness in that period. As a result of a decrease in solar radiation, less sensible heat was exchanged between the city and the overlying air. The influence of weather conditions on $Q_{H}$ is also visible in July; in July 2010 and 2012, the air temperature is relatively high as compared to the long-term average (Fig. 4). The precipitation totals in July 2010 are almost at the same level as the long-term average, but in July 2012 rainfall is significantly smaller (only 35\% of the long-term average). A large difference in $Q^{*}$ at noon, even exceeding $100 \mathrm{~W} \mathrm{~m}^{-2}$, is also observed between those months; however, $Q_{H}$ remains almost the same. This results from different circulation conditions i.e. more frequent inflow from more vegetated areas. In July 2012, the inflow from the south and west prevails. South and west of the LAS path, there are sparsely built-up areas with a relatively high vegetation fraction; during the inflow from these directions, a smaller $Q_{H}$ is observed, because the latent heat flux played a more important role in the heat exchange than $Q_{H}$. This can also be confirmed by comparing the $Q_{H} / Q^{*}$ ratio. In July 2010 at noon, $Q_{H} / Q^{*}$ reached almost 0.47 , while in July 2012 this was only approximately 0.37 . The relatively cold and wet July 2011 clearly stands out, because at noon $Q_{H}$ is almost the same magnitude as in September or even October.

In the analyzed period the lowest diurnal $Q_{H}$ are observed in the November 2010 and 2012. However, due to the lack of a sufficient amount of data it should not be considered as a rule that the lowest $Q_{H}$ always occurs in late autumn. The measurements of $Q_{H}$ from other city centres suggest that the lowest $Q_{H}$ is most likely to occur in winter (Christen and Vogt 2004; Goldbach and Kuttler 2013; Kotthaus and Grimmond 2014a). On the other hand, in densely built-up areas an addition of heat from fuel combustion could lead to an enhancement of $Q_{H}$ or even positive night-time $Q_{H}$ during winter (e.g. Offerle et al. 2005).

In large cities, $Q_{H}$ could remain positive throughout the day (e.g. Oke et al. 1999; Grimmond et al. 2004; Christen and Vogt 2004; Offerle et al. 2006b; Kotthaus and Grimmond 2014a). In Łódź, we found that most of the time the night-time flux is negative, however, in several months (e.g. January, February, June) it was found to be positive, especially when the inflow from over the city centre dominates. The LAS source area during the night, especially when the wind speed is often lower than during the day, is several times larger than under unstable conditions that prevail during the day. Therefore, the resulting $Q_{H}$ from the LAS instrument is the average flux from the densely built-up city centre, the outskirts and sometimes even the vegetated areas outside the city (Fig. 6).

In January and February, the daytime $Q_{H}$ reaches $150 \mathrm{~W} \mathrm{~m}^{-2}$ and in December approximately $100 \mathrm{~W} \mathrm{~m}^{-2}$. The daytime $Q_{H}$ in winter ranges from 40 to $80 \mathrm{~W} \mathrm{~m}^{-2}$, while during the night negative values prevail in December, and positive in January and February. Almost all wintertime data were collected during the 2011/2012 winter, therefore the results are not representative for a longer period. In addition, the majority of scintillometer data for January and February were collected under cold advection conditions, which may have led to the domination of positive night-time $Q_{H}$. In March, the daytime $Q_{H}$ value on average reaches $100 \mathrm{~W} \mathrm{~m}^{-2}$, but frequently exceeds $150 \mathrm{~W} \mathrm{~m}^{-2}$ with a maximum of about $250 \mathrm{~W} \mathrm{~m}^{-2}$. During the night, negative $Q_{H}$ prevails in March. Over $75 \%$ of daytime $Q_{H}$ values in April is larger than $50 \mathrm{~W} \mathrm{~m}^{-2}$ and reaches up to $300 \mathrm{~W} \mathrm{~m}^{-2}$. In April, the largest negative values of $Q_{H}\left(-75 \mathrm{~W} \mathrm{~m}^{-2}\right)$ in the whole measurement campaign are observed just around sunrise on 22 April 2011 under conditions of strong warm advection. On average, the largest $Q_{H}$ values are observed in May (median approximately $120 \mathrm{~W} \mathrm{~m}^{-2}$ ); however, the maximum values of $Q_{H}\left(>400 \mathrm{~W} \mathrm{~m}^{-2}\right)$ were recorded during the strong cold advection $\left(7.5^{\circ} \mathrm{C}\right.$ temperature drop) on 13 June 2010. In the middle of summer, a relatively low $Q_{H}$ is observed, but the maximum values reaches a similar level as in May. Negative $Q_{H}$ values are observed more often in August than in June. The length of day rapidly decreases in autumn in Poland, therefore, 


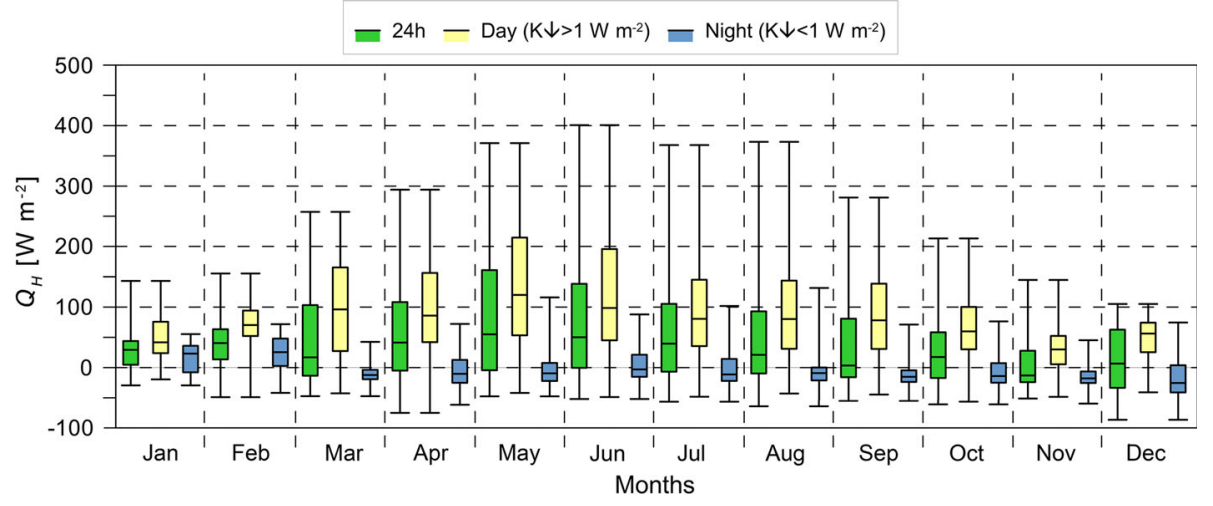

Fig. 6 Annual variability of turbulent sensible heat flux $Q_{H}$ measured with the scintillometer in Łódź in the period 2009-2011. Whisker-box plot: minimum, 1st quartile, median, 3rd quartile, maximum. $K \downarrow$ is the downward shortwave radiation flux

less solar radiation reaches the surface. As a result, $Q_{H}$ rapidly decreases towards the end of the year. In September, the maximum $Q_{H}$ reaches almost $290 \mathrm{~W} \mathrm{~m}^{-2}$, but in November it is only $150 \mathrm{~W} \mathrm{~m}^{-2}$. In autumn the negative values of $Q_{H}$ prevail during the night; the lowest $Q_{H}$ values are observed (the whole day median is negative, approximately $-10 \mathrm{~W} \mathrm{~m}^{-2}$ ) in November. This possibly results from low data availability for winter months, because results from other cities suggest that the lowest $Q_{H}$ is more likely to occur in winter (e.g. Christen and Vogt 2004; Goldbach and Kuttler 2013; Kotthaus and Grimmond 2014a). On the other hand, in the city centre the release of a large amount of additional heat from fuel combustion (transportation, heating), significantly enhances $Q_{H}$, as even at night it remains positive, i.e. heat is transported upward from the surface. The long-term eddy-covariance measurements in the centre of Łódź (Fortuniak 2010; Fortuniak et al. 2013) suggest that in December $Q_{H}$ remains positive even at night.

\section{Dependence of Turbulent Sensible Heat Flux on Wind Direction}

The high diversity of the urban surface is one of the factors causing the dependence of $Q_{H}$ on wind direction. The optical path of our LAS instrument traversed the south-eastern edge of the city centre; thus, the set-up of an LAS instrument in Łódź enables an analysis of $Q_{H}$ under the inflow from the densely built-up areas of the city centre (Fig. 7a) and from the rather sparsely built-up areas with a relatively large vegetation fraction (Fig. 7b). The average $Q_{H}$ from the dense settlement is positive almost throughout the day, except for autumn and December, when negative $Q_{H}$ is observed during the night. But even for that part of the year $Q_{H}$ turns negative some time after the sunset. It seems that for the inflow from the western and northern sectors, the diurnal cycle of $Q_{H}$ in Łódź had features characteristic of city centres (e.g. Christen and Vogt 2004; Lagouarde et al. 2006; Kotthaus and Grimmond 2014a, b). For the less dense settlement, the night-time $Q_{H}$ is almost always negative, except for January and February. For the areas located south-east of the LAS path, $Q_{H}$ changes sign around sunrise and sunset, and on average at noon it is about $10-20 \mathrm{~W} \mathrm{~m}^{-2}$ lower than for the city. Such a diurnal cycle of $Q_{H}$ is rather characteristic of suburban areas (e.g. Grimmond and Oke 1999; Offerle et al. 2006a, b; Ward et al. 2013, 2014). The differences between 

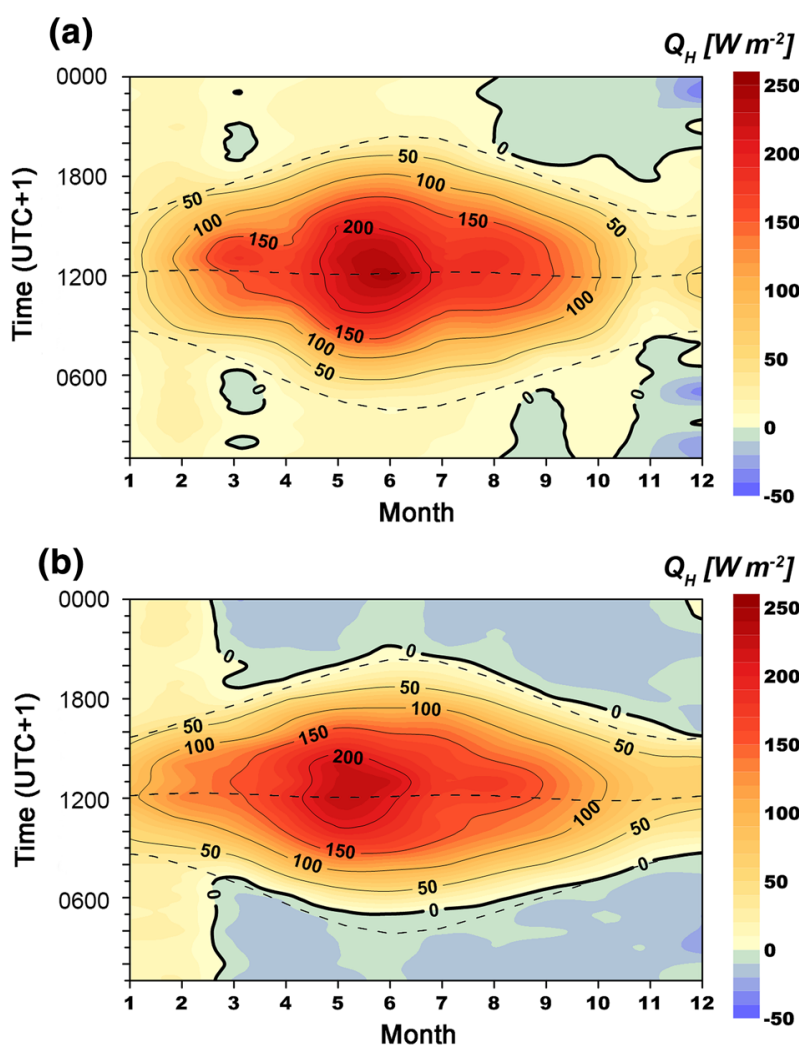

Fig. 7 Average diurnal cycle of turbulent sensible heat flux $\left(Q_{H}\right)$ in the period August 2009-November 2011 in Łódź for cases with inflow from the city centre (a) and other directions (b)

the diurnal cycle of $Q_{H}$ on both sides of the LAS path confirm the ability of a single LAS instrument to provide $Q_{H}$ values for different surface types inside the city.

The probability density function (PDF) provides more insight into the wind direction dependence of $Q_{H}$ (Fig. 8). During the day low $Q_{H}$ (approximately $60 \mathrm{Wm}^{-2}$ ) is the most frequent feature for the south-western inflow (Fig. 8a), and for that direction, $Q_{H}$ exceeding $200 \mathrm{~W} \mathrm{~m}^{-2}$ rarely occurrs, but values close to zero are more frequent than for inflow from other directions. Negative daytime values of $Q_{H}$ are most commonly observed during the inflow from the south-east. The PDF peak for south-east flows is close to $50 \mathrm{~W} \mathrm{~m}^{-2}$, but contrary to south-west flows the heat flux frequently exceeds $150 \mathrm{~W} \mathrm{~m}^{-2}$. There are many post-industrial sites to the south-east, which are occupied with large old buildings with mostly tarred roofs, enhancing heat accumulation during the day. Under unstable conditions, the LAS source area is relatively small and includes these post-industrial areas. Despite a large vegetation fraction in that part of the city, the presence of areas with large buildings and a large fraction of impervious surface causes an increase of area-averaged $Q_{H}$. For the inflow from western and eastern areas, the peak of PDF is close to $50 \mathrm{~W} \mathrm{~m}^{-2}$; however, $Q_{H}$ exceeding $200 \mathrm{~W} \mathrm{~m}^{-2}$ is more frequent for the eastern direction. On the whole, the largest $Q_{H}\left(>300 \mathrm{~W} \mathrm{~m}^{-2}\right)$ is observed under the inflow from the city centre, i.e. the north and north-western directions, but also for the inflow from the north-east. While in the city centre the high occurrence of large $Q_{H}$ is not surprising, for the north-eastern sector, which 


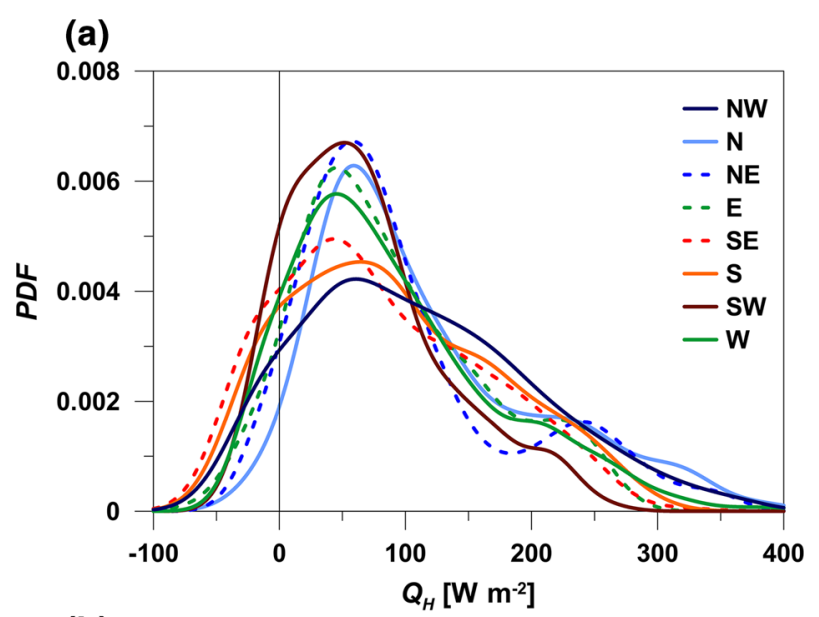

(b)

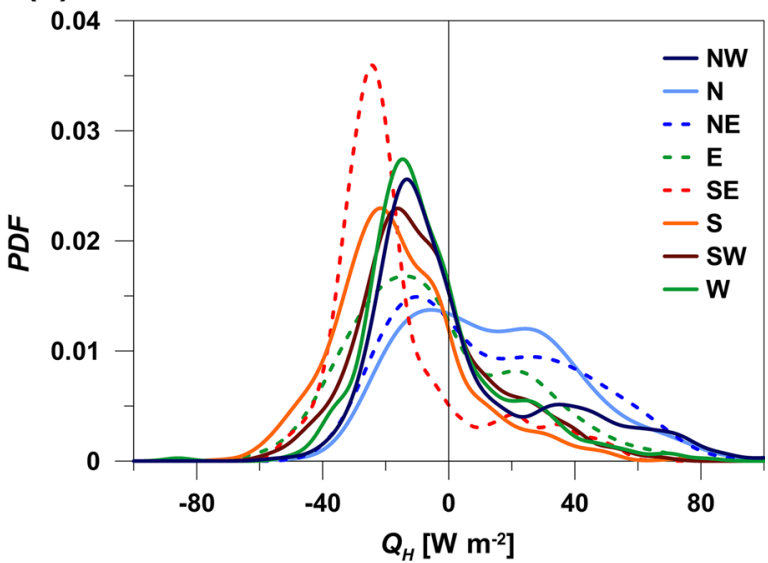

Fig. 8 Probability density function $(P D F)$ for turbulent sensible heat flux depending on wind direction for daytime (a) and night-time (b)

has a large pervious-surface fraction (approximately 25\% under unstable conditions), it is quite unexpected. One of the possible explanations is that even under the inflow from the north-east, the LAS source area comprises a large part of the city centre; thus $Q_{H}$ from that area could significantly increase the average $Q_{H}$ for the whole source area. When stability approaches near-neutral conditions, the source area expands and comprises more and more pervious surfaces (e.g. part of the forest located north-east of the city centre), the overall $Q_{H}$ in the LAS source areas is relatively low. It is confirmed by the PDF for the northeastern inflow, i.e. the frequency of $Q_{H}$ in the range $150-250 \mathrm{~W} \mathrm{~m}^{-2}$ is relatively low. To some extent, the situation is similar for the northern inflow, i.e. the PDF has lower values of approximately $180-220 \mathrm{~W} \mathrm{~m}^{-2}$. The city centre is surrounded by several green areas to the north and north-east. Under weak unstable conditions or low wind speed these areas could significantly contribute to the $Q_{H}$ measured with the LAS instrument. The city centre contributes most to the observed fluxes for the north-western inflow, which is also depicted in the PDF. The PDF maximum is approximately $50-60 \mathrm{~W} \mathrm{~m}^{-2}$, but it is lower than for other directions. In addition, for the north-western inflow the frequency of $Q_{H}$ exceeding 
$100 \mathrm{~W} \mathrm{~m}^{-2}$ is the highest (almost $50 \%$ ). In contrast, for the south-western inflow almost $50 \%$ of the observed heat flux is lower than $60 \mathrm{~W} \mathrm{~m}^{-2}$.

To some extent, the shape of the PDF for the night-time $Q_{H}$ depends on the method of determining the sign of $Q_{H}$ (Fig. 8b). The sign of the flux was established based on $Q_{H}$ from eddy-covariance measurements, and data from both towers were used. To reflect the similarities of the LAS and eddy-covariance source areas, data from Lipowa ware used for the $330^{\circ}-130^{\circ}$ wind directions and data from Narutowicza for the others. Therefore, the results presented for the night should be analyzed with caution. Nevertheless, for the inflow from the north and north-east, $Q_{H}$ at night is positive for 64 and $58 \%$ of time, respectively. For these directions the peak of PDF is approximately $-10 \mathrm{~W} \mathrm{~m}^{-2}$. A relatively low occurrence (approximately 40\%) of positive nighttime $Q_{H}$ is observed for the north-west, which is surprising, since during the inflow from that direction (city centre) the largest frequency of positive $Q_{H}$ is expected. It seems that the flux sign determination method could have failed to some extent. For the south-eastern inflow, positive $Q_{H}$ is the rarest (only $17 \%$ of cases). Moreover, $Q_{H}$ lower than $-20 \mathrm{~W} \mathrm{~m}^{-2}$ is the most frequent for the south-eastern inflow, with a peak at $-30 \mathrm{~W} \mathrm{~m}^{-2}$. For the inflow from the south, positive $Q_{H}$ is also rarely observed (19\% of cases). For the remaining wind directions, the PDF peak is approximately $-15 \mathrm{~W} \mathrm{~m}^{-2}$, and positive $Q_{H}$ is observed $30-35 \%$ of time.

In Fig. 9a, b, the relation between $Q_{H}$ and inflow direction is shown, where the dependence of $Q_{H}$ on wind direction results from two factors. The first is the impervious-surface fraction: under unstable conditions, which prevail in urban areas, the artificial-surface fraction is almost always $>80 \%$. However, for the sector $355^{\circ}-090^{\circ}$ it never exceeds $85 \%$ and for the sector $195^{\circ}-325^{\circ}$ it never falls below that threshold. In addition, for the sector $190^{\circ}-320^{\circ}$ a lesser diversity in the impervious-surface fraction is observed. As the centre of the LAS path is located closer to the eastern edge of the city core during the inflow from $190^{\circ}-320^{\circ}$, the almost entire LAS source area extends over the fairly uniform city centre with a small vegetation fraction. On the other hand, for the rest of the directions only the surface close to the LAS path is covered with dense development. Farther from the city centre the vegetation fraction grows and the LAS source area covers several green parks surrounding the old-city core. Taking into account the artificial-surface fraction, the expected $Q_{H}$ should be slightly higher during the inflow from the city centre than from the less developed areas.

Another factor important for the $Q_{H}$ variability is the weather, notably warm and cold advection (Fig. 9d). Herein, a day-to-day temperature change exceeding 1.5 and $2.5^{\circ} \mathrm{C}$ is considered as weak and strong advection, respectively. When cold air masses pass over a relatively warm urban surface, the sensible heat exchange between the surface and the overlying air is significantly enhanced. For instance, the highest daily $Q_{H}$ in the city centre of Łódź was observed under strong cold advection. On the other hand, when warm air masses flow over the city, they usually significantly decrease the amount of heat transported upward from the surface. When warm advection occurs in winter, or after relatively cold periods, heat is transported downward to the city surface, resulting in negative $Q_{H}$. Also the precipitation affects the flux partitioning; after rainfall the latent heat flux is enhanced, while $Q_{H}$ is frequently diminished.

The largest $Q_{H}$ (maximum $350-400 \mathrm{~W} \mathrm{~m}^{-1}$ ) is observed under the inflow from $260^{\circ}$ to $50^{\circ}$. For these directions, also the daytime $Q_{H}$ median is relatively high, often exceeding $100 \mathrm{~W} \mathrm{~m}^{-2}$. A relatively low $Q_{H}$ (maximum approximately $250 \mathrm{~W} \mathrm{~m}^{-2}$ ) is found for the $190^{\circ}-250^{\circ}$ wind direction, even though one could expect $Q_{H}$ to be larger, as the centre of the LAS source area extends over dense settlement (Fig. 9c). Generally during the day the $Q_{H}$ median ranges from about $57 \mathrm{~W} \mathrm{~m}^{-2}$ (wind sector $120^{\circ}-130^{\circ}$ to nearly $120 \mathrm{~W} \mathrm{~m}^{-2}$ $\left(300^{\circ}-310^{\circ}\right)$. For the night-time $Q_{H}$ median is positive in the sector $330^{\circ}-050^{\circ}$ and negative 
(a) 400
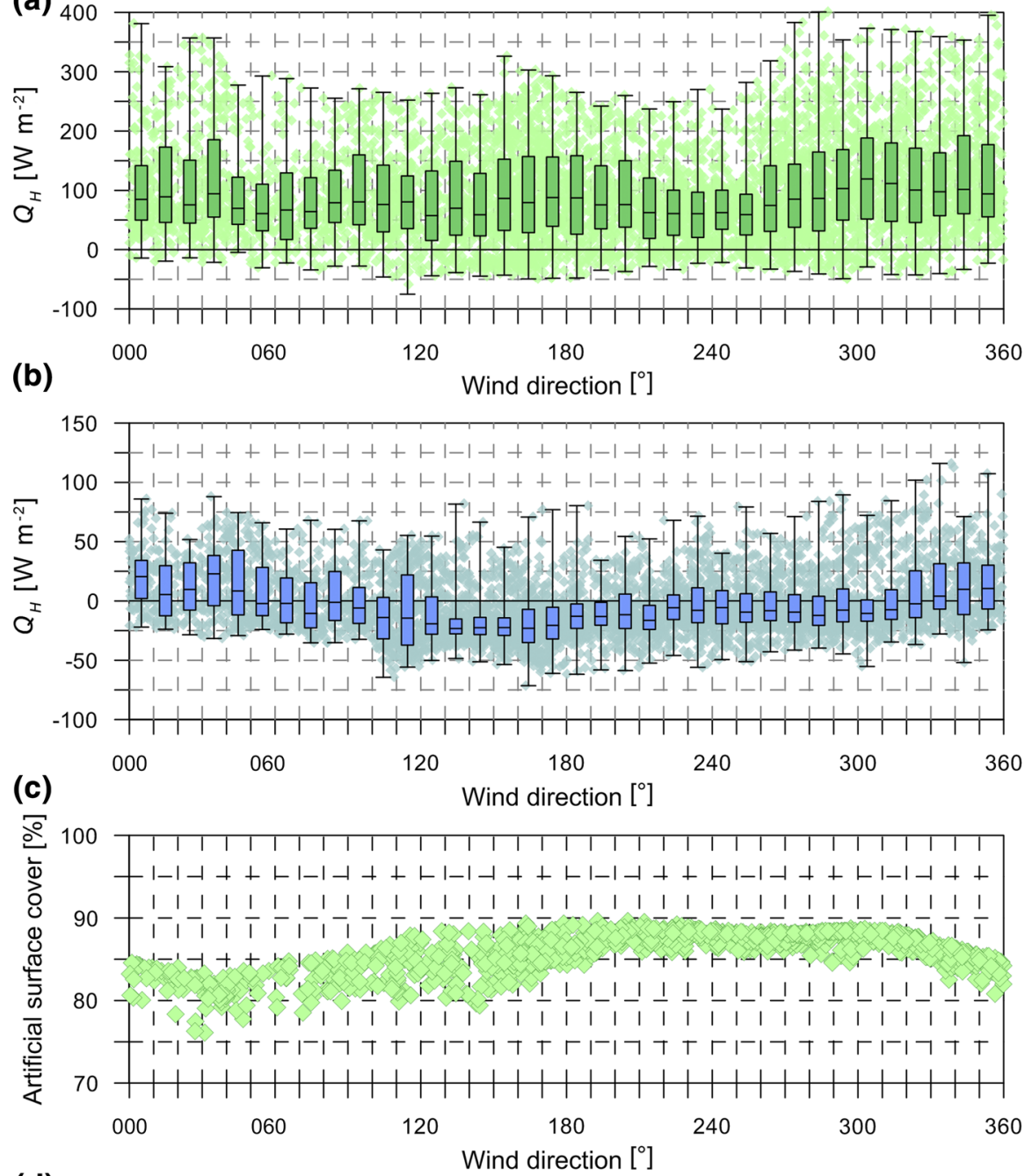

(d)

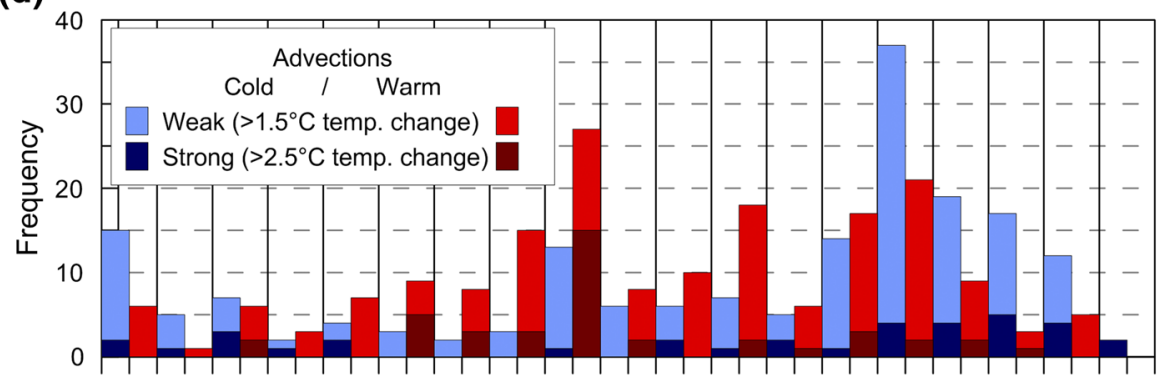

$-010010030050070090110130150170190210230250270290310330350370$ Wind direction $\left[{ }^{\circ}\right]$

Fig. 9 Turbulent sensible heat flux $\left(Q_{H}\right)$ during the day (a) and night (b), artificial surface cover fraction (c), and frequency of cold/warm advections for $20^{\circ}$ bins (d) depending on wind direction observed at the Narutowicza site 
for other directions. There are two sectors for which more than $75 \%$ of the observed $Q_{H}$ are negative, i.e. $130^{\circ}-200^{\circ}$ and $220^{\circ}-230^{\circ}$.

The weather conditions also play a vital role in the sensible heat exchange between the city and the overlying air. The increasing maximum daytime $Q_{H}$ and the more frequent positive nighttime $Q_{H}$ strongly corresponds to the frequency of cold advection (Fig. 9d). The day-to-day air temperature drops of $1.5^{\circ} \mathrm{C}$ are the most frequent under the inflow from $250^{\circ}-010^{\circ}$. On the other hand, the most frequent large and negative $Q_{H}$ values re observed for the wind direction favourable for warm advection.

For negative $Q_{H}$, its strong variability associated with wind direction is also observed. For the inflow from $345^{\circ}$ to $095^{\circ}$, the absolute $Q_{H}$ is almost twice as small $\left(Q_{H}>-25 \mathrm{~W} \mathrm{~m}^{-2}\right)$ as for the inflow from $095^{\circ}$ to $200^{\circ}$ when frequently $Q_{H}$ drops below $-50 \mathrm{~W} \mathrm{~m}^{-2}$. For stable conditions, the LAS source area can extend far outside the city centre, i.e. heat can be transported over relatively far distances, which significantly complicates an analysis of the observed night-time fluxes. The LAS instrument provides only the absolute value of $Q_{H}$; therefore one should be cautious when analyzing $Q_{H}$ under stable conditions.

To isolate anthropogenic and weather influences on $Q_{H}$, Crawford et al. (2017) applied the conditional sampling for their dataset. With the aid of high-resolution radar data on precipitation they were able to distinguish 'wet' and 'dry' days. Next, they investigated the differences between weekday and weekend observations of $Q_{H}$. Their results indicate that even after the rainfall $Q_{H}$ magnitude is still positively/negatively correlated with building/vegetation fraction. For our dataset such detailed analysis is not possible because neither the high-resolution data on precipitation nor data on citizens activity were available. Nevertheless, we attempt to isolate surface cover and weather influences on the $Q_{H}$ magnitude. In May 2011 the rain gauge was mounted at Narutowicza station and it registered 1-h precipitation totals. Therefore, we are able to distinguish the $Q_{H}$ observations from the periods after the rainfall or when the surface was dry. During the measurement campaign over the $75 \%$ of precipitation occurred during the inflow from just four directions i.e. west (30\%), north-west (18\%), south-west (17\%) and north (10\%). Only 3 and 5\% of rainfall occurred during the eastern and north-eastern inflow, respectively. As a result the number of data available for cases with wet surface is significantly reduced for south, south-east, east and north-east directions.

Kotthaus and Grimmond (2014a) showed that Bowen ratio can be reduced even $12 \mathrm{~h}$ after the rain. Therefore we decided to treat all observations from periods up to $12 \mathrm{~h}$ after the precipitation, as cases with wet surface, even though Crawford et al. (2017) used only $3 \mathrm{~h}$ threshold for London. The application of small threshold for our dataset will make further analysis impossible, due to low data availability. All observations taken at least $12 \mathrm{~h}$ after the rainfall are treated as cases with dry surface. In addition, we have decided to divide all 'dry' cases to observations taken under the cold or warm advection ( $78 \%$ of cases) and without any advections ( $22 \%$ of cases). We have limited our analysis only to midday hours (1100-1400 local time), because negative flux is frequently observed at early morning or at evening in Łódź. All sampled $Q_{H}$ values were binned in $20^{\circ}$ sectors. For each sector average $Q_{H}$ values for midday hours were calculated and then compared with fraction of artificial surfaces (Fig. 10).

Despite low data availability, for both wet and dry surface conditions the average midday $Q_{H}$ seems to correlate with the fraction of artificial surface, but this correlation is very weak. During the wet surface conditions, $Q_{H}$ values at noon are significantly reduced (on average $38 \mathrm{~W} \mathrm{~m}^{-2}$ ) in comparison to observations taken during dry surface conditions. In addition the strongest linear relation between $Q_{H}$ and land cover is found for wet surface conditions. When only dry surface conditions are considered, significant differences in $Q_{H}$ dependence on land cover between the times with cold/warm advections and without any advections were 
Fig. 10 Average turbulent sensible heat flux $\left(Q_{H}\right)$ and artificial surface cover (\%) of $20^{\circ}$ wind sector bins at midday (1100-1400 h). 'Wet' stands for $Q_{H}$ registered up to $12 \mathrm{~h}$ after the rainfall, while 'dry' define all observations taken at least $12 \mathrm{~h}$ after the last rainfall. In addition, 'dry' conditions were sampled for days with cold/warm advections, and without any significant day to day temperature change. Note that only bins with $>5$ observations were shown
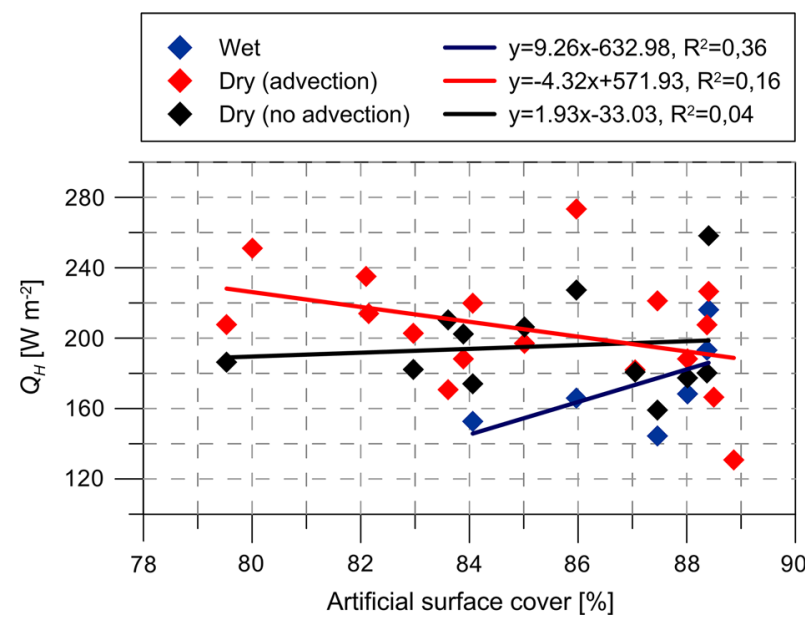

found. When cold or warm air inflow occurs over the city, it seems that the relation between the $Q_{H}$ magnitude and artificial surface cover vanishes. An increase in fraction of artificial surface cover is not followed by increase in $Q_{H}$ any longer.

It seems that weather conditions have a greater influence on wind direction dependent $Q_{H}$ variability, than the surface cover in the LAS source area, in case of Łódź. When there is no cold/warm advection over the city area, an increase in artificial surface fraction in LAS source area is followed by an increase in $Q_{H}$.

\section{Summary and Conclusions}

Long-term scintillometer measurements of turbulent sensible heat flux in the city centre of Łódź, Poland are presented, with consideration given to the temporal variability, as well as to the dependence on wind direction. A large variability of the source-area characteristics is observed in Łódź. The largest fraction (approximately 90\%) of impervious surface is found under unstable conditions and the inflow from the north-west and west, i.e. the city centre. When stability approaches neutral, a large fraction of pervious surface is observed, as the source area includes more surfaces covered with vegetation that lie outside the centre. For near-neutral conditions, artificial surfaces cover up to $75 \%$ of the scintillometer source area. In contrast, under stable stratification when the source area frequently extends outside the city, the surfaces covered with vegetation prevails (approximately $70 \%$ ), especially for the north-eastern inflow.

The largest $Q_{H}$ is observed in May and June, when at noon it reaches $230 \mathrm{~W} \mathrm{~m}^{-2}$, on average. For most of the year, negative night-time $Q_{H}$ is observed, except for January and February, when possibly the anthropogenic heat flux is responsible for positive $Q_{H}$. In addition, positive $Q_{H}$ at night is observed in months with frequent cold advection (e.g. June 2010). Frequent precipitation and relatively low air temperature in July results in a decrease of $Q_{H}$, which at noon has features characteristic of dense urban areas: the diurnal peak is observed $1-2 \mathrm{~h}$ later than the maximum of radiation balance; it turns negative several hours later than $Q *$. Even though in the city centre positive $Q_{H}$ is frequently observed throughout the day (Christen and Vogt 2004; Goldbach and Kuttler 2013; Kotthaus and Grimmond 2014a), in Łódź it is observed almost only in winter and during several months with 
frequent cold advection. When the $Q_{H}$ measurements are performed with eddy covariance techniques, the source area is relatively small and can cover relatively uniform surfaces, e.g. dense development. For an LAS instrument located in the city, the source area frequently comprises different surfaces, a lot of them being pervious. The resulting average $Q_{H}$ for the LAS source area could be positive or negative, depending on other factors, e.g., wind direction.

A high year-to-year variability of $Q_{H}$ is observed in Łódź, mostly because of varying weather conditions. For instance, when large precipitation totals are observed, the latent heat flux is enhanced and therefore lower $Q_{H}$ is observed (e.g. July 2011).

To some extent, the scintillometer measurements could also be used for an analysis of the spatial variability of $Q_{H}$. It is possible due to the large source area of the LAS that could include different surface types, e.g., for Łódź it covers the city centre or less developed settlements. In our case, the largest $Q_{H}$ s found for the inflow from the north and north-west, i.e. the most densely built-up part of the city. For these directions, the maximum $Q_{H}$ is almost $100 \mathrm{~W} \mathrm{~m}^{-2}$ larger than for the inflow from areas with larger pervious surface fractions. In addition, for the inflow from the city centre positive $Q_{H}$ at night is observed more frequently. Large discrepancies between areas located approximately north and south of the LAS path are also found for the $Q_{H} / Q^{*}$ ratio. For most of the time, in the case of the inflow from the city centre, sensible heat flux accounts for approximately $60 \%$ of net radiation, while during the inflow from more vegetated areas it it "only" approximately $40 \%$.

The surface cover is a vital factor of the $Q_{H}$ dependence on inflow direction, but not the only one; weather conditions, especially cold and warm advection, play an equally important role. For our dataset, weather conditions seems to play an even more important role than the surface cover. Differences in the amount of artificial surfaces affect $Q_{H}$ mostly during calm and sunny weather, without any cold or warm advection. For this reason $Q_{H}$ is not strongly correlated with building or vegetation fraction, as it is in other cities e.g. Basel (Christen and Vogt 2004), Swindon (Ward et al. 2014), London (Crawford et al. 2017). As highlighted by Ward et al. (2015b), there is still a need for long-term scintillometer measurements of sensible and latent heat fluxes in urban areas that capture both the seasonal and inter-annual variability. Therefore, such long-term measurement campaigns could help determine to what extent the observed variability of heat fluxes is caused by different surface characteristics or by weather conditions.

Acknowledgements The present work was funded by the Polish National Science Centre under Grant 2011/01/N/ST10/07529 in the years 2011-2014 and by the Polish Ministry of Science and Higher Education under Grant N306 276935 in the years 2008-2011.

Open Access This article is distributed under the terms of the Creative Commons Attribution 4.0 International License (http://creativecommons.org/licenses/by/4.0/), which permits unrestricted use, distribution, and reproduction in any medium, provided you give appropriate credit to the original author(s) and the source, provide a link to the Creative Commons license, and indicate if changes were made.

\section{References}

Andreas EL (1988) Estimating $C_{n}^{2}$ over snow and sea ice from meteorological data. J Opt Soc Am A 5:481-495 Beyrich F, De Bruin HAR, Meijninger WML, Schipper JW, Lohse H (2002) Results from one-year continuous operation of a large aperture scintillometer over a heterogeneous land surface. Boundary-Layer Meteorol 105:85-97 
Beyrich F, Bange J, Hartogensis OK, Raasch S, Braam M, van Dinther D, Gräf D, van Kesteren B, van den Koonenberg AC, Maronga B, Martin S, Moene AF (2012) Towards a validation of scintillometer measurements: the LITFASS-2009 experiment. Boundary-Layer Meteorol 144:83-112

Christen A, Vogt R (2004) Energy and radiation balance of a central European city. Int J Climatol 24:1395-1421

Clifford S, Ochs G, Lawrence R (1974) Saturation of optical scintillation by strong turbulence. J Opt Soc Am 64:148-154

Crawford B, Grimmond CSB, Ward HC, Morrison W, Kotthaus S (2017) Spatial and temporal patterns of surface-atmosphere energy exchange in a dense urban environment using scintillometry. Q J R Meteorol Soc 143:817-833

De Bruin HAR, Kohsiek W, Van den Hurk BJJM (1993) A verification of some methods to determine the fluxes of momentum, sensible heat and water vapour using standard deviation and structure parameter of scalar meteorological quantities. Boundary-Layer Meteorol 63:231-257

De Bruin HAR, Van den Hurk BJJM, Kohsiek W (1995) The scintillation method tested over a dry vineyard area. Boundary-Layer Meteorol 76:25-40

Evans JG, McNeil DD, Finch JW, Murray T, Harding RJ, Ward HC, Verhoef A (2012) Determination of turbulent heat fluxes using a large aperture scintillometer over undulating mixed agricultural terrain. Agric For Meteorol 166(167):221-233

Ezzachar J, Chehbouni A, Hoedjes JCB, Chehbouni AH (2007) On the application of scintillometry over heterogeneous grids. J Hydrol 334:493-501

Fortuniak K, Pawlak W, Siedlecki M (2013) Integral turbulence statistics over a Central European city centre. Boundary-Layer Meteorol 146:257-276

Fortuniak K (2010) Radiative and turbulent components of heat balance of urban terrain—Łódź case study, University of Łódź Press, Łódź (in Polish)

Frehlich RG, Ochs GR (1990) Effects of saturation on the optical scintillometer. Appl Opt 29:548-553

Göckede M, Markkanen T, Maunder M, Arnold K, Leps J-P, Foken T (2005) Validation of footprint models using natural tracer measurements from a field experiment. Agric Forest Meteorol 135:314-325

Goldbach A, Kuttler W (2013) Quantification of turbulent heat fluxes for adaptation strategies within urban planning. Int J Climatol 33:143-159. https://doi.org/10.1002/joc.3437

Green AE, McAneney KJ, Astill MS (1994) Surface layer scintillation measurements of daytime heat and momentum fluxes. Boundary-Layer Meteorol 68:357-373

Grimmond CSB, Oke TR (1999) Aerodynamic properties of urban areas derived from analysis of surface form. J Appl Meteorol 38:1262-1292

Grimmond CSB, Salmond JA, Oke TR, Offerle B, Lemonsu A (2004) Flux and turbulence measurements at a densely built-up site in Marseille: heat, mass (water and carbon dioxide), and momentum. J Geophys Res 109:D24101

Hartogensis OK, Watts CJ, Rodriguez J-C, De Bruin HAR (2003) Derivation of an effective height for scintillometers: La Poza experiment in Northwest Mexico. J Hydrometeorol 4:915-928

Hsieh CI, Katul G, Chi T (2000) An approximate analytical model for footprint estimation of scalar fluxes in thermally stratified atmospheric flows. Adv Water Resour 23:765-772

Hill RJ, Clifford SF, Lawrence RS (1980) Refractive index and absorption fluctuations in the infrared caused by temperature, humidity and pressure fluctuations. J Opt Soc Am 70:1192-1205

Hill RJ, Ochs GR, Wilson JJ (1992) Heat and momentum using optical scintillation. Boundary-Layer Meteorol 58:391-408

Hoedjes JCB, Chehbouni A, Ezzachar J, Escadafal R, De Bruin HAR (2007) Comparison of large aperture scintillometer and eddy covariance measurements: Can thermal infrared data be used to capture footprintinduced differences? J Hydrometeorol 8:144-159

Horst TW, Weil JC (1992) Footprint estimation for scalar flux measurements in the atmospheric surface layer. Boundary-Layer Meteorol 59:279-296

Kanda M, Moriwaki R, Roth M, Oke T (2002) Area-averaged sensible heat flux and a new method to determine zero-plane displacement length over an urban surface using scintillometry. Boundary-Layer Meteorol 105:177-193

Kooijmans LMJ, Hartogensis OK (2016) Surface-layer similarity functions for dissipation rate and structure parameters of temperature and humidity based on eleven field experiments. Boundary-Layer Meteorol 160:501-527

Kotthaus S, Grimmond CSB (2014a) Energy exchange in a dense urban environment-Part I: temporal variability of long-term observations in central London. Urban Clim 10:261-280. https://doi.org/10.1016/j. uclim.2013.10.002

Kotthaus S, Grimmond CSB (2014b) Energy exchange in a dense urban environment—Part II: impact of spatial heterogeneity of the surface. Urban Clim 10:281-307. https://doi.org/10.1016/j.uclim.2013.10. 001 
Lagouarde J-P, Irvine M, Bonnefond J-M, Grimmond CSB, Long N, Oke TR, Salmond JA, Offerle B (2006) Monitoring the sensible heat flux over urban areas using large aperture scintillometery: case study of Marseille city during the ESCOMPTE experiment. Boundary-Layer Meteorol 118:449-476

Leclerc MY, Shen SH, Lamb B (1997) Observations and large eddy simulation modeling of footprints in the lower convective boundary layer. J Geophys Res 102:9323-9334

Meijninger WML, Hartogensis OK, Kohsiek W, Hoedjes JCB, Zuurbier RM, De Bruin HAR (2002) Determination of area-averaged sensible heat fluxes with a large aperture scintillometer over a heterogeneous surface-Flevoland field experiment. Boundary-Layer Meteorol 105:37-62

Meijninger WML, Beyrich F, Lüdi A, Kohsiek W, De Bruin HAR (2006) Scintillometer-based turbulent fluxes of sensible and latent heat over a heteregeneous land surface-a contribution to LITFASS-2003. Boundary-Layer Meteorol 121:89-110

Moene AF (2003) Effects of water vapour on the structure parameter of the refractive index for near-infrared radiation. Boundary-Layer Meteorol 107:635-653

Nordbo A, Järvi L, Haapanala S, Moilanen J, Vesala T (2013) Intra-city variation in urban morphology and turbulence structure in Helsinki, Finland. Boundary-Layer Meteorol 146:469-496

Ochs GR, Wilson JJ (1993) A second-generation large aperture scintillometer, NOAA Tech. Memor. ERL ETL-232, NOAA Environmental Research Laboratories, Boulder, CO, USA

Offerle B, Grimmond CSB, Fortuniak K (2005) Heat storage and anthropogenic heat flux in relation to the energy balance of a central European city centre. Int J Climatol 25:1405-1419

Offerle B, Grimmond CSB, Fortuniak K, Kłysik K, Oke TR (2006a) Temporal variations in heat fluxes over a central European city centre. Theor Appl Climatol 84:103-115

Offerle B, Grimmond CSB, Fortuniak K, Pawlak W (2006b) Intra-urban differences of surface energy fluxes in a central European city. J Appl Meteorol Climatol 45:125-136

Oke TR (1982) The energetic basis of the urban heat island. Q J R Meteorol Soc 108:1-24

Oke TR (1988) The urban energy balance. Prog Phys Geogr 12:471-508

Oke TR, Spronken-Smith RA, Jauregui E, Grimmond CSB (1999) The energy balance of central Mexico City during the dry season. Atmos Environ 33:3919-3930

Pauscher L (2010) Scintillometer measurements above the urban area of London. University of Bayreuth, Bayreuth

Pawlak W, Fortuniak K, Siedlecki M (2011) Carbon dioxide flux in the centre of Łódź, Poland—analysis of a 2-year eddy covariance measurement data set. Int J Climatol 31:232-243

Pawlak W, Fortuniak K (2016) Eddy covariance measurements of the net turbulent methane flux in the city centre-results of 2-year campaign in Łódź, Poland. Atmos Chem Phys 16:8281-8294. https://doi.org/10. 5194/acp-16-8281-2016

Roth M, Salmond JA, Satyanarayana ANV (2006) Methodological considerations regarding the measurement of turbulent fluxes in the urban roughness sublayer: the role of scintillometery. Boundary-Layer Meteorol 121:351-375

Salmond JA, Roth M, Oke TR, Christen A, Voogt JA (2012) Can surface-cover tiles be summed to give neighborhood fluxes in cities? J Appl Meteorol Clim 51:133-149

Samain B, Defloor W, Pauwels VRN (2012) Continuous time series of catchment-averaged sensible heat flux from a large aperture scintillometer: efficient estimation of stability conditions and importance of fluxes under stable conditions. J Hydrometeorol 13:423-442

Schmid HP (1994) Source areas for scalar and scalar fluxes. Boundary-Layer Meteorol 67:293-318

Schmid HP (1997) Experimental design for flux measurements: matching scales of observations and fluxes. Agric For Meteorol 87:179-200

Stanhill G, Kalma JD (1995) Solar dimming and urban heating at Hong Kong. Int J Climatol 15:933-941

Timmermans WJ, Su Z, Olioso A (2009) Footprint issues in scintillometry over heterogeneous landscapes. Hydrol Earth Syst Sci 13:2179-2190

Thiermann V, Grassl H (1992) The measurement of turbulent surface layer fluxes by use of bichromatic scintillation. Boundary-Layer Meteorol 58:367-391

Tunick A, Rachele H, Hansen FV, Howell TA, Steiner JL, Schneider AD, Evett SR (1994) REBAL '92-a cooperative radiation and energy balance field study for imagery and electromagnetic propagation. Bull Am Meteorol Soc 75:421-430

Wang TI, Ochs GR, Clifford SF (1978) A saturation-resistant optical scintillometer to measure $\mathrm{C}_{\mathrm{n}}^{2}$. J Opt Soc Am 69:334-338

Ward HC, Evans JG, Grimmond CSB (2013) Multi-season eddy covariance observations of energy, water and carbon fluxes over a suburban area in Swindon, UK. Atmos Chem Phys 13:4645-4666

Ward HC, Evans JG, Grimmond CSB (2014) Multi-scale sensible heat fluxes in the suburban environment from large aperture scintillometry and eddy covariance. Boundary Layer-Meteorol 165:65-89 
Ward HC, Evans JG, Grimmond CSB, Bradford J (2015a) Infrared and millimetre-wave scintillometry in the suburban environment-Part 1: structure parameters. Atmos Meas Tech 8:1385-1405. https://doi.org/ 10.5194/amt-8-1407-2015

Ward HC, Evans JG, Grimmond CSB (2015b) Infrared and millimetre-wave scintillometry in the suburban environment-Part 2: large-area sensible and latent heat fluxes. Atmos Meas Tech 8:1407-1424. https:// doi.org/10.5194/amt-8-1407-2015

Wesely ML (1976) The combined effect of temperature and humidity on the refractive index. J Appl Meteorol 15:43-49

Wood CR, Kouznetsov RD, Gierens R, Nordbo A, Järvi L, Kallistratova MA, Kukkonen J (2013a) On the temperature structure parameter and sensible heat flux over Helsinki from sonic anemometry and scintillometry. J Atmos Ocean Technol 30:1604-1615

Wood CR, Pauscher L, Ward HC, Kotthaus S, Barlow JF, Gouvea M, Lane SE, Grimmond CSB (2013b) Wind observations above an urban river using a new lidar technique, scintillometry and anemometry. Sci Total Environ 442:527-533

Wyngaard JC, Izumi Y, Collins SA (1971) Behaviour of refractive-index-structure parameter near the ground. J Opt Soc Am 61:1646-1650

Zhang H, Zhang H (2015) Comparison of turbulent sensible heat flux determined by large-aperture scintillometer and eddy covariance over urban and suburban areas. Boundary-Layer Meteorol 154:119-136. https://doi.org/10.1007/s10546-014-9965-8

Zieliński M, Fortuniak K, Pawlak W, Siedlecki M (2013) Turbulent sensible heat flux in Łódź, Central Poland, obtained from scintillometer and eddy covariance measurements. Meteorol Z 22(5):603-613

Zieliński M, Fortuniak K, Pawlak W, Siedlecki M (2017) Influence of mean rooftop level estimation method on sensible heat flux retrieved from a large aperture scintillometer over a city centre. Boundary-Layer Meteorol 164:281-301 